\title{
Clinical application of electrophysiological markers in the differential diagnosis of depression and very mild Alzheimer's disease
}

\author{
G R J Swanwick, M Rowan, R F Coen, D O’Mahony, H Lee, B A Lawlor, J B Walsh, \\ D Coakley
}

\begin{abstract}
Background-Current evidence indicates that, on their own, neither flash visual evoked responses (FVEPs) nor event related potentials (ERPs) are sufficiently useful to the clinician in the very early stages of memory dysfunction. However, the possibilities for the combined use of these measures has not been fully explored.

Methods-This study examined the clinical utility of combined FVEP and ERPP300 component latencies as predictive markers in 16 patients with Alzheimer's disease, 15 patients with depression, and
\end{abstract} 21 control subjects.

Results-There were significant group differences in FVEP P2 latency $(P=0 \cdot 004)$ between the controls and both the depressive patients and those with very mild Alzheimer's disease. There were no statistically significant group differences for the ERP component (N2/P300) amplitudes or latencies. The P300 component latency was positively correlated with both the FVEP N2 and FVEP $P 2$ component latencies in the patients with Alzheimer's disease but not in the control subjects or the depressed patients. A discriminant function, using two ERP and two FVEP component measures, gave an overall correct classification rate for dementia of $78 \%$. In this study of very mildly impaired patients the FVEP latencies provided a more sensitive marker for the presence of cognitive dysfunction than P300 latency delay. Conclusions-The findings support the use of multimodal evoked potentials in the differential diagnosis of very mild Alzheimer's disease and normal aging.

(F Neurol Neurosurg Psychiatry 1996;60:82-86)

Keywords: electrophysiology; depression; Alzheimer's disease

In elderly patients the differential diagnosis of depression and the very early stages of Alzheimer's disease poses a common clinical dilemma. Similar cognitive impairments can occur in both disorders and, in addition, Alzheimer's disease is not infrequently complicated by clinical depression. ${ }^{1-3}$

In 1976 Visser et al reported that components of the flash visual evoked potential
(FVEP) were delayed in dementia. ${ }^{4}$ Several research groups have since documented FVEP latency delays in Alzheimer's disease. ${ }^{5.8} \mathrm{By}$ contrast, Coben et al ${ }^{9}$ and Ray et $a l^{10}$ reported no significant delays in FVEP latencies in mild to moderate Alzheimer's disease. Although the findings of Philpot $e t a l^{8}$ provided evidence for FVEP P2 delay in Alzheimer's disease this was only significant in patients under 75 years of age.

Investigators using VEPs in depressed patients have concentrated on amplitude rather than latency abnormalities. Perris ${ }^{11}$ and Shagass et $a^{12}$ reported lower VEP amplitudes in depression and psychotic depression respectively, whereas Vasconetto et $a l^{13}$ reported augmentation. Khanna et $a l^{14}$ showed accentuation of some FVEP waveforms in young melancholic patients whereas Knot and Lapierre ${ }^{15}$ reported attenuation of FVEP potentials in patients with psychomotor retardation. More recently Vasile et $a l^{16}$ have reported FVEP abnormalities in melancholia which were most prominent in elderly patients. However, some investigators-for example, Guidi et $a l^{17}$-have failed to show any difference between depressed patients and normal controls.

Goodin $e t a^{18}$ were the first to suggest that P300 latency delay might provide a sensitive and specific marker for dementia. The claims of high sensitivity for dementia were supported by further studies. ${ }^{19-22}$ However, these studies used moderately demented patients and, although one recent study ${ }^{23}$ did show a significant P300 delay in patients with mild Alzheimer's disease, there are studies which suggest that P300 latency delay does not have sufficient sensitivity during the early stages of Alzheimer's disease when it would be most useful to the clinician. ${ }^{32426}$

Goodin $^{27}$ also suggested that delayed P300 latency could be used to distinguish patients with "true" dementia from the "pseudodementia" that can be associated with depression and other "functional" disorders. Unfortunately, the medical literature is far from unanimous on this issue. Abnormalities of P300 in depression have been reported by both Pfefferbaum et $a l^{24}$ and Gordon et al. ${ }^{22}$ Furthermore, Patterson et $a l^{25}$ and Kraiuhin et $a l^{3}$ failed, using an auditory "oddball" paradigm, to discriminate patients with mild Alzheimer's disease from depressive patients.

Thus current evidence indicates that, on their own, neither VEPs nor event related potentials (ERPs) are sufficiently sensitive or 
specific in the very early stages of memory dysfunction to be useful to the clinician. However, the possibilities for the combined use of these measures has not been fully explored. For example, a Medline literature search identified no studies published in English which have used combined VEP and ERP ("multimodal") measures. The one article identified (published in Japanese) did show the utility of multimodal EPs in the differential diagnosis of Alzheimer's disease, dementia of Parkinson's disease, and Binswanger's disease. ${ }^{28}$

The aim of this study was to assess the clinical utility of combined FVEP and ERP-P300 component latencies as predictive markers in patients presenting with mild cognitive impairment who could otherwise only be distinguished as normal or as having either Alzheimer's disease or depression by a period of follow up.

\section{Methods}

SUBJECTS

Sixteen patients with very mild Alzheimer's disease and 15 age matched patients who met DSM-III-R criteria for a major depressive episode ${ }^{29}$ were recruited. The Alzheimer's disease group consisted of four men and 12 women with a mean age of 71.4 (SD 6.9) and a mean mini mental state examination $(\mathrm{MMSE})^{30}$ score of 23.9 (SD $2 \cdot 4$ ). The depressive patients were seven men and eight women with a mean age of $74 \cdot 2(\mathrm{SD} 7 \cdot 1)$ and a mean MMSE score of $25 \cdot 8$ (SD 3.5). Electrophysiological data were also recorded from 21 healthy controls. These were seven men and 14 women with a mean age of $70 \cdot 1$ (SD 6.9). All of these control subjects had an MMSE score of 28 or greater.

At the time of assessment all of the patients with Alzheimer's disease had very mild cognitive impairment as defined by an MMSE score of $\geqslant 20$ and a clinical dementia rating $(\mathrm{CDR})^{31}$ of $0.5 /$ "questionable dementia." All of these CDR 0.5 patients were followed up to ensure progression from "questionable dementia" to CDR $1 /$ mild dementia meeting NINCDSADRDA criteria for probable Alzheimer's disease. ${ }^{32}$ All of the evoked potential measurements were carried out at the initial assessment and any patients who had not progressed within 12 months were excluded from the analysis. Any patient with Alzheimer's disease who fulfilled DSM-III-R criteria for depression was also excluded.

The depressed patients were followed up for a minimum of 12 months to ensure that any cognitive deficits did not progress. (In addition to the 15 depressed patients entered into the study for analysis, five patients who initially met DSM-III-R criteria for a major depressive episode later met DSM-III-R criteria for dementia. These five patients were excluded from the analysis because they had dual pathology.) Severity of depression was assessed with the Hamilton scale for depression (Ham-D). ${ }^{33}$ The mean Ham-D for the depressed patients was $20 \cdot 8$ (SD 4.6). Electro- physiological measurements were carried out before response to treatment. The aim was to examine the clinical application of evoked potentials and, as any technique that requires patients to be drug free or to have a wash out period will be of limited practical use, it was not appropriate to withhold antidepressants from depressed patients. However, the inclusion of patients on medication did have implications for the choice of electophysiological variable to be measured. Benzodiazepines have been reported to produce a reduction ${ }^{34}$ and imipramine an increase ${ }^{35}$ in FVEP amplitude but FEVP latency effects have not been convincingly shown. Given these facts it was intended that latency measures only would be considered.

The control subjects were fully independent in the community. They had no history of psychiatric disorder, neurological disorder, cognitive symptoms, alcohol dependence, or substance misuse and were not on psychotropic medication. The study was approved by the Federated Dublin Voluntary Hospitals ethics committee and informed consent was obtained from each subject.

\section{ELECTROPHYSIOLOGICAL PROCEDURES:}

ERP RECORDING

Recordings were carried out, within three hours of eating either breakfast or lunch, in a sound and electrically attenuated room with the temperature kept relatively constant $\left(18-20^{\circ} \mathrm{C}\right)$. Time of day and seasonal factors were matched across the diagnostic groups. Subjects were seated in a comfortable chair and were trained to respond to the target stimuli by raising the index finger of the dominant hand.

The responses were recorded from frontal $(\mathrm{Fz})$, vertex $(\mathrm{Cz})$, and parietal $(\mathrm{Pz})$ midline electrode sites with a left mastoid reference using an auditory "oddball" paradigm generated by the Medelec "Mistral II" system. A midline forehead electrode was used to monitor eyeblink artifact. The stimuli used were binaural tones with a frequency of $2000 \mathrm{~Hz}$ for the target tones, which amounted to $15 \%$ of stimuli presented, and $1000 \mathrm{~Hz}$ for the non-target tones. Once the subject had responded correctly to 32 target stimuli the procedure was discontinued. Signals were filtered using a $0 \cdot 1-30 \mathrm{~Hz}$ bandwidth and amplified by a factor of $5 \times 10^{4}$. The P300 component was defined as the largest positive peak occurring after the N1, P2, and N2 components which increased in amplitude from the frontal to the parietal scalp areas. The P3MAX method ${ }^{36}$ was employed to identify the P300 component latency when bifurcated peaks occurred. The $\mathrm{Fz}$ and $\mathrm{Cz}$ electrodes were included to assist in P300 component identification and the analyses were restricted to the $\mathrm{Pz}$ recordings.

\section{ELECTROPHYSIOLOGICAL PROCEDURES:} FVEP RECORDING

The FVEPs were recorded using left (O1) and right (O2) occipital electrode sites referenced to $\mathrm{Fz}$ (midline frontal site). Binocular flash stimuli were presented at a rate of $2 \mathrm{~Hz}$ using a 
stroboscope placed $30 \mathrm{~cm}$ from the eye. The stroboscope was triggered by a Medelec "Mistral II" system. A filter band width of $0 \cdot 1-30 \mathrm{~Hz}$ was applied and the response signals were amplified by a factor of $5 \times 10^{4}$. Taking a mean from the two channels (O1, $\mathrm{O} 2)$, the N2 and P2 components were derived from 128 averaged evoked response sweeps.

DATA ANALYSIS

Group differences for each type of measure were assessed using analyses of variance (ANOVA) and post hoc Scheffe's $F$ tests. The electrophysiological measures giving the strongest findings from the FVEP and ERP studies were then combined by multivariate discriminant analysis. Using minitab statistical software a discriminant analysis was applied with the aim of classifying the findings into two groups (dementia $v$ no dementia). The data from the depressed patients and the control subjects were classified together as the primary aim was to distinguish Alzheimer's disease from other diagnostic groups rather than depressed patients from controls. To compensate for an optimistic apparent error rate (AER) a cross validation procedure was also applied to the data. This procedure omits the first observation from the data set, develops a classification function using the remaining observations, then classifies the omitted observation. Next, it returns the first observation to the data and repeats the process with the remaining observations. ${ }^{37}$

\section{Results}

There was no significant age difference between the groups (ANOVA: $P=0 \cdot 23$ ). The FVEP N2 and P2 components were well formed in all 52 subjects. Similarily, the ERP P300 component peak was identifiable at the $\mathrm{Pz}$ electrode site in all subjects; however, the $\mathrm{N} 2$ component was not clearly identifiable in two subjects. None of the FVEP or ERP component measures (FVEP N2 and P2 latencies, ERP N2 and P300 latencies and amplitudes) were significantly correlated with either the degree of depression (Ham-D) or the degree of dementia (MMSE).

\section{FVEP COMPONENT LATENCIES}

There was a statistical trend towards a group difference in FVEP N2 latency between the depressive patients and the healthy controls

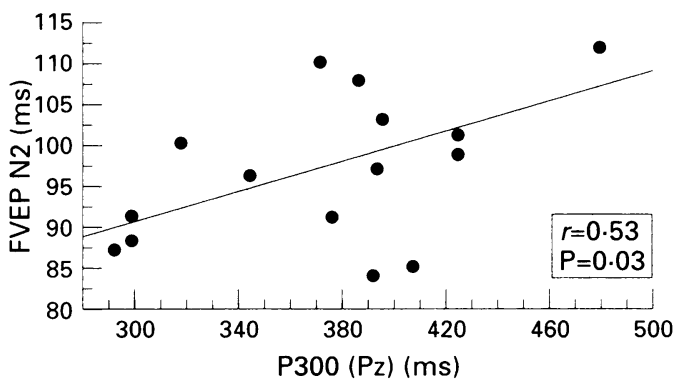

Figure 1 Relation between FVEP N2 and P300 latencies in Alzheimer's disease. with the latency being delayed in the depressive patients (ANOVA: $\mathrm{P}=0.08$; post hoc Scheffe's $F$ test: $2 \cdot 03$ ). There was no FVEP $\mathrm{N} 2$ latency delay in the patients with very mild Alzheimer's disease relative to the controls. There were significant group differences in FVEP P2 latency (ANOVA: $P=0.004$ ) between the controls and both the depressives (post hoc Scheffe's $F$ test $=4 \cdot 2$ ) and the patients with very mild Alzheimer's disease (post hoc Scheffe's $F$ test $=4 \cdot 5$ ).

\section{ERP COMPONENT MEASURES}

There were no statistically significant group differences for the ERP component (N2/ P300) amplitudes or latencies.

The P300 component latency was positively correlated with both the FVEP N2 and FVEP P2 component latencies in the patients with Alzheimer's disease but not in the control subjects or the depressed patients. The correlations between the P300 and FVEP latencies in the Alzheimer's disease group were as follows: P300 and FVEP N2 $(r=0.53$, $\mathrm{P}=0.03 ;$ fig 1$) ; \mathrm{P} 300$ and FVEP P2 $(r=0.76, \mathrm{P}=0.0006$; fig 2$)$. For the ERP $\mathrm{N} 2$ and FVEP N2/P2 latencies the correlations were $r=0.49$ and $r=0.54$, respectively.

Thus both patient groups showed FVEP latency delays but the pattern of abnormality was different and was only correlated with the ERP latencies in the patients with Alzheimer's disease.

DISCRIMINANT FUNCTION ANALYSIS

The strongest findings from the FVEP and P300 recordings were FVEP N2/P2 latency abnormalities in both the patients with Alzheimer's disease and depressed patients and positive correlations between the ERP $\mathrm{N} 2 / \mathrm{P} 300$ and the FVEP N2/P2 latencies in the patients with Alzheimer's disease. Thus four variables were used for the discriminant function analysis - namely, the FVEP N2/P2 latencies and the ERP N2/P300 latencies recorded from the $\mathrm{Pz}$ electrode site.

The resulting discriminant analysis (table 1) gave an overall correct classification rate of $78 \%$. Twelve of the 15 patients with Alzheimer's disease ( $80 \%$ sensitivity) were correctly classified as having a dementia, whereas 27 of the 35 combined controls and depressive patients were correctly classified as not demented ( $80 \%$ specificity).

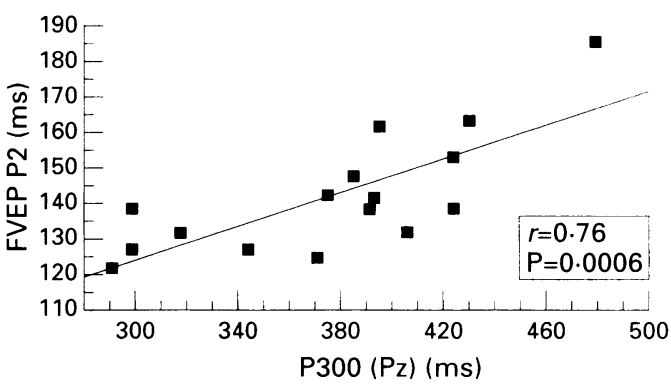

Figure 2 Relation between FVEP P2 and P300 latencies in Alzheimer's disease. 
Table 1 Linear discriminant function

\begin{tabular}{lcr}
\hline $\begin{array}{l}\text { Linear discriminant } \\
\text { function for group: }\end{array}$ & $\begin{array}{l}\text { Alzheimer's } \\
\text { disease }\end{array}$ & $\begin{array}{l}\text { Non- } \\
\text { demented }\end{array}$ \\
\hline Constant & -63.463 & -62.065 \\
ERP N2 & 0.153 & 0.146 \\
ERP P300 & 0.063 & 0.066 \\
FVEP N2 & 0.437 & 0.528 \\
FVEP P2 & 0.150 & 0.079 \\
\hline
\end{tabular}

Squared distance between groups $=1 \cdot 168$.

To compensate for an optimistic AER the cross validation procedure was applied to the same data set giving an overall correct classification rate of $72 \%$. Ten of the 15 patients with Alzheimer's disease (67\% sensitivity) were correctly classified, whereas 26 of the 35 combined controls and depressive patients were correctly classified as not demented (74\% specificity).

As the success of the discriminant analysis might primarily reflect differences between patients with Alzheimer's disease and the controls, analyses were also carried out to discriminate the patients with Alzheimer's disease from the depressive patients and the controls separately. As it is also possible that the FVEP measures could be equally successful on their own the analyses were repeated using only the two FVEP component latencies. The discriminant analysis for the patients with Alzheimer's disease versus control subjects was the most successful and the addition of the ERP measures to the FVEP latencies was only helpful for this same comparison (table 2).

\section{Discussion}

In recent years there has been a growing disappointment in the clinical utility of evoked potential measures. There is little doubt that there are significant group differences between moderately demented subjects and controls. By contrast, the quest for an electrophysiological marker with sufficient sensitivity and specificity to diagnose mild Alzheimer's disease in individual patients has been much less fruitful.

The patients with Alzheimer's disease in this study had such early symptoms (CDR 0.5 / questionable dementia) that a period of follow up (6-48 months) was required to ensure progressive cognitive impairment and confirm the diagnosis. Therefore, given that most recent studies have reported that P300 latency delay has poor sensitivity for cognitive dysfunction in the early stages of Alzheimer's disease, ${ }^{3}{ }^{24-26}$ it was not surprising that comparison of P300 latencies in this study failed to discriminate the

Table 2 Discriminant analysis for groups separately using combined ERP and FVEP measures or FVEP measures alone

\begin{tabular}{llll}
\hline $\begin{array}{l}\text { Groups to be } \\
\text { discriminated }\end{array}$ & $\begin{array}{l}\text { Measures } \\
\text { used }\end{array}$ & $\begin{array}{l}\text { Sensitivity for } A D \\
(\%)\end{array}$ & $\begin{array}{l}\text { Specificity for } A D \\
(\%)\end{array}$ \\
\hline $\mathrm{AD} v$ "no dementia" & ERP and FVEP & 80 & 77 \\
& FVEP alone & 73 & 77 \\
$\mathrm{AD} v$ controls & ERP and FVEP & 87 & 85 \\
$\mathrm{AD} v$ depressives & FVEP alone & 73 & 85 \\
& ERP and FVEP & 73 & 60 \\
& FVEP alone & 67 & 67 \\
\hline
\end{tabular}

$\mathrm{AD}=$ Alzheimer's disease. patients with very early Alzheimer's disease from either the depressed patients or the control subjects.

On the other hand there was a significant delay in the FVEP P2 component in both of the two patient groups relative to the controls. Additionally, there was a significant delay in the FVEP $\mathrm{N} 2$ in the depressive patients relative to the controls. These findings add further support to the medical literature on FVEP abnormalities in depression, particularly as previous studies had concentrated on amplitude rather than latency. Although the depressed patients were not drug free and pharmacological effects on the findings cannot be completely excluded, the use of latency rather than amplitude measures makes this less likely. For the same reason a sex effect was unlikely to have a significant influence on the findings. However, it cannot be ruled out as the proportion of men was greatest in the depressed group.

The group difference in FVEP P2 latency between the patients with very mild Alzheimer's disease and the controls in the current study is of particular interest given the previous negative findings of Coben $e t a l^{9}$ and Ray et $a l .{ }^{10}$ The study reported by Ray et $a l^{10}$ included only six controls and six patients and may not have had sufficient power to show a difference. Neither of the previous studies used the NINCDS-ADRDA criteria for selection of patients with Alzheimer's disease. Therefore, differences in the clinical diagnostic criteria provide another possible explanation for the contrasting findings in the present study.

As there was an almost complete overlap in the range of MMSE scores in the Alzheimer's disease (20-27) and depressed (16-30) patients the two patient groups reflected the common clinical dilemma posed by the differential diagnosis of very mild cognitive dysfunction. The present findings suggest that FVEP measures may provide a more sensitive marker for cognitive dysfunction than P300 measures. Although the FVEP findings were not specific for dementia there was an indication that in combination with P300 measures they might have diagnostic utility. The finding of a strong correlation between the P300 component and FVEP component latencies in the patients with Alzheimer's disease but no relation in the depressive patients might indicate different pathophysiological processes underlying the FVEP abnormalities in the two groups. Furthermore, it adds support to the notion that "multimodal" EPs might provide a more sensitive and more specific marker for Alzheimer's disease in patients with mild cognitive impairment.

Although the approach was less successful at discriminating very mild Alzheimer's disease from cognitive impairment secondary to depression, the finding that a discriminant function, using two ERP and two FVEP component measures, was a useful diagnostic validator in very mildly impaired patients is promising and provides further support for this approach. This will clearly need to be 
replicated on an independent group of patients. However, the results of the cross validation analysis are also encouraging.

\section{Conclusions}

In this study of very mildly impaired patients the FVEP latencies provided a more sensitive marker for the presence of cognitive dysfunction than P300 latency delay. The FVEP abnormalities were not specific for dementia. However, the findings did suggest that different pathophysiological processes might be responsible for the latency delays in the two patient groups. Thus the present findings support the use of multimodal evoked potentials in the differential diagnosis of very mild Alzheimer's disease and normal aging but additional measures (for example, pattern reversal VEPs) may need to be added if this approach is to have a role in discriminating very mild Alzheimer's disease from cognitive impairment secondary to depression.

We thank Irene Bruce and Fiona Buggy, Mercer's Institute for Research on Ageing, for their invaluable assistance with the running of this study. GRJS is a Health Research Board Research Fellow.

1 Lazarus LW, Newton N, Cohler B, Lesser J, Schweon C. Frequency and presentation of depressive symptoms in patients with primary degenerative dementia. $\mathrm{Am}$ patients with primary dege

2 McClean S. Assessing dementia. Part 1. Difficulties, definitions and differential diagnosis. Aust NZ $\mathcal{f}$ Psychiatry tions and differ

3 Kraiuhin C, Gordon E, Coyle S, Sara G, Rennie C, Howson A, et al. Normal latency of the P300 eventrelated potential in mild-to-moderate Alzheimer's disease and depression. Biol Psychiatry 1990;28:372-86.

4 Visser SL, Stam FC, Van Tilburg W, Op Den Velde W, Blom JL, De Rijke W. Visual evoked response in senile and presenile dementia. Electroencephalogr Clin Neurophysiol 1976;40:385-92.

5 Harding GFA, Dogget CE, Orwin A, Smith EJ. Visual evoked potentials in pre-senile dementia. In: Spekreijse H, Apkarian PA, eds. Documenta Ophthalmologica Series No 27. The Hague: Junk Publishers, 1981:193-202.

6 Cosi V, Vitelli E, Gozzoli L, Corona A, Ceroni M, Callieco $\mathrm{R}$. Visual evoked potentials in aging of the brain. In: R. Visual evoked potentials in aging of the brain. In:
Courjon J, Mauguiere F, Revol M, eds. Clinical applicaCourjon J, Mauguiere F, Revol M, eds. Clinical applica-
tions of evoked potentials in neurology. New York: Raven tions of evoked poten

7 Wright CE, Harding GFA, Orwin A. Pre-senile dementiathe use of the flash and pattern VEP in diagnosis Electroencephalogr Clin Neurophysiol 1984;57: 405-15.

8 Philpot M, Amin D, Levy R. Visual evoked potentials in Alzheimer's disease: correlations with age and severity. Electroencephalogr Clin Neurophysiol 1990;77:323-9.

9 Coben LA, Danziger WL, Hughes CP. Visual evoked potentials in mild senile dementia of Alzheimer type. Electroencephalogr Clin Neurophysiol 1983;55:121-30.

10 Ray PG, Meador KJ, Loring DW, Murro AM, Buccafusco $\mathrm{J}$, Yang $\mathrm{X}-\mathrm{H}$, et al. Effects of scopolamine on visual evoked potentials in aging and dementia. Electroencephalogr Clin Neurophysiol 1991;80:347-51.

11 Perris C. EEG techniques in the measurement of the severity of depressive syndromes. Neuropsychobiology 1975; 1:16-25.

12 Shagass C, Roemer RA, Straumanis J Jr, Amadeo M. Topography of sensory potentials in depressive disorders. Biol Psychol 1980;15:183-207.
13 Vasconetto C, Floris V, Morocutti C. Visual evoked responses in normal and psychiatric subjects. Electroencephalogr Clin Neurophysiol 1971;31:77-83

14 Khanna S, Mukundan CR, Channabasavanna SM. Middle latency evoked potentials in melancholic depression. Biol Psychol 1989;25:494-8.

15 Knott VJ, Lapierre YD. Electrophysiological and behavioral correlates of psychomotor responsivity in depression. Biol Psychol 1987;22:313-24.

16 Vasile RG, Duffy FH, McAnulty G, Mooney JJ, Bloomingdale K, Schildkraut JJ. Abnormal visual evoked response in Melancholia: A replication study. Biol Psychiatry 1992;31:325-36.

17 Guidi M, Scarpino O, Angeleri F. Topographic EEG and visual evoked potentials in elderly subjects, depressed patients, and demented patients. Psychiatry Res 1989; 29:403-6.

18 Goodin DS, Squires KC, Starr A. Long latency eventrelated components of the auditory evoked potential in related components of the auditory
dementia. Brain 1978;101:635-48.

19 Squires KC, Chippendale TJ, Wrege KS, Goodin DS, Starr A. Electrophysiological assessment of mental function in aging and dementia. In: Poon LW, ed. Aging in the 1980s. Washington, DC: American Psychological Association, 1980:125.

20 Brown WS, Marsh JT, LaRue A. Event-related potentials in psychiatry: differentiating depression and dementia in the elderly. Bull LA Neurol Soc 1982;47:91-107.

21 Syndulko K, Hansch EC, Cohen SN, Pearce JW, Goldberg Z, Montan B, et al. Long-latency event-related potentials in normal aging and dementia. In: Courjon J, Mauguiere $\mathrm{F}$, Revol M, eds. Clinical applications of evoked potentials in neurology. New York: Raven Press, 1982:279-85.

22 Gordon E, Kraiuhin C, Harris A, Meares R, Howson A. The differential diagnosis of dementia using P300 latency. Biol Psychiatry 1986;21:1123-32.

23 Marsh JT, Schubarth G, Brown WS, Riege W, Strandburg $\mathrm{RM}$, Dorsey D, et al. PET and P300 relationships in early Alzheimer's disease. Neurobiol Aging 1990;11: 471-76.

24 Pfefferbaum A, Wenegrat BG, Ford JM, Roth WT, Kopell BS. Clinical application of the P3 component of eventrelated potentials. II. Dementia, depression and schizophrenia. Electroencephalogr Clin Neurophysiol 1984;59: 104-24.

25 Patterson JV, Michalewski HJ, Starr A. Latency variability of the components of auditory event-related potentials to infrequent stimuli in aging, Alzheimer-type dementia, and depression. Electroencephalogr Clin Neurophysiol 1988; 71:450-60.

26 Neshige R, Barrett G, Shibasaki H. Auditory long-latency event-related potentials in Alzheimer's disease and multiinfarct dementia. F Neurol Neurosurg Psychiatry 1988; $51: 1120-5$

27 Goodin DS. Event-related (endogenous) potentials. In: Aminoff MJ, ed. Electrodiagnosis in clinical neurology. New York : Churchill Livingstone, 1986:575-95.

28 Takeda $M$, Tachibana H, Sugita $M$. Multimodal evoked potentials in patients with dementia. Nippon Ronen Igakkai Zasshi 1993;30:1058-67.

29 American Psychiatric Association. Diagnostic and statistical manual of mental disorders, 3rd ed-revised (DSM-III-R), Washington, DC:APA, 1987

30 Folstein MF, Folstein SE, McHugh PR. 'Mini-mental state': a practical method for grading the cognitive state
of patients for the clinician. $\mathcal{F}$ Psychiatr Res $1975 ; 12: 189-$ 98 .

31 Hughes CP, Berg L, Danziger WL, Coben LA, Martin RL. A new scale for the staging of dementia. $B r \mathcal{F}$ Psychiatry 1982;140:566-72.

32 McKhann G, Drachman D, Folstein M, Katzman R, Price $D$, Stadlan EM. Clinical diagnosis of Alzheimer's disease: Report of the NINCDS-ADRDA Work Group under the auspices of Department of Health and Human Services Task force on Alzheimer's Disease. Neurology 1984;34:939-44.

33 Hamilton $\mathbf{M}$. Development of a rating scale for primary depressive illness. British fournal of Social and Clinical Psychology 1967;6:278-96.

34 Bond AJ, Lader $\mathrm{MH}$. The residual effects of flurazepam. Psychopharmacologia 1973;32:223-35.

35 Endo S, Nakayama S, Kuraoka Y, Matsumura T, Kubota I, Hirose $S$, et al. Changes in visual evoked potentials induced by imipramine in patients with endogenous induced by imipramine in patients with endogenous
depression. Nippon Ika Daigaku Zasshi 1983;50:480-8.

36 Polich J. P300 in clinical applications: meaning, method, and measurement. Am $\mathcal{f} E E G$ Technol 1991;31: and $201-31$.

37 Johnson R, Wichern D. Applied multivariate satistical methods. 2nd ed. London: Prentice Hall, 1988. 